\title{
Status of Rohingya in Refugee Camps of Bangladesh: A Review Study
}

\author{
Shahnam Karin1, Md. Arif Chowdhury ${ }^{2 *}$, Md. Abul Hasnat ${ }^{3}$, Nusrat Jahan Tarin ${ }^{2}$ \\ ${ }^{1}$ The United Nations Children's Fund (UNICEF), Cox's Bazar, Bangladesh \\ ${ }^{2}$ Institute of Water and Flood Management, Bangladesh University of Engineering and Technology, Dhaka, Bangladesh \\ ${ }^{3}$ Institute of Forestry and Environmental Sciences, University of Chittagong, Chittagong, Bangladesh \\ Email: *arifchowdhury065@gmail.com
}

How to cite this paper: Karin, S., Chowdhury, Md.A., Hasnat, Md.A. and Tarin, N.J. (2020) Status of Rohingya in Refugee Camps of Bangladesh: A Review Study. Open Access Library Journal, 7: e6575.

https://doi.org/10.4236/oalib.1106575

Received: July 4, 2020

Accepted: September 13, 2020

Published: September 16, 2020

Copyright $\odot 2020$ by author(s) and Open Access Library Inc.

This work is licensed under the Creative Commons Attribution International License (CC BY 4.0).

http://creativecommons.org/licenses/by/4.0/

\begin{abstract}
More than 500,000 Rohingya refugees are living in the refugee camps of Cox's Bazar in Bangladesh, where the living conditions are ominous. Most of the families are deprived of enough food and sustained livelihood. This review study was conducted to understand the present status of Rohingyas with Bangladesh Government's stand and that of international community as well. This study also focused on the humanitarian responses, forestry and wild life, disaster risk management, shelter facilities, WASH activities, health facilities, adolescent sexual reproductive health, gender-based violence, and human trafficking to understand the current situation of Rohingya refugees in camps. This study will help national and international stakeholders to take necessary steps to manage Rohingya refugees in camps of Cox Bazar, Bangladesh.
\end{abstract}

\section{Subject Areas}

Sociology

\section{Keywords}

Rohingya Refugees, Humanitarian Responses, Forestry and Wild Life, Education, Health, Gender, Human Trafficking, Shelter, Disaster Risk Management

\section{Introduction}

Rohingyas are the Muslim minorities, who belong to the western state of Rakhaine, Myanmar [1]. These people have been undergoing overwhelming suppression and exploitation for decades [2], starting from 1978 [3], while the most recent situation in 2017 [4] causing more than 950,000 refugees to enter Bangla- 
desh fleeing from Myanmar [5] and to look for shelter in the refugee camps of Bangladesh [6]. It was reportedly the belief of the United Nations that expulsion of the Rohingya Muslims from Rakhine was the intention of the Myanmar regime [7]. Also, Amnesty International, in a statement claimed that Rohingyas are trapped in discrimination supported by the state [8].

As around a million Rohingyas live in the camps in the border of Bangladesh and Myanmar, they have to go through ominous living conditions. Most of the families are deprived of enough food and sustained livelihood [9]. Insufficient food supply, little to no access to education, and restrictions in movement are the main challenges Rohingyas at camps have to encounter [10] [11] [12] [13]. The refugees have to dwell in fragilely constructed shelters made of bamboo, brick and mud and where extreme heat and no ventilation facility make it very unhygienic [14]. Majority of the refugees are living in makeshift overcrowded shelters in Cox's Bazar and Bandarban [5]. Water contamination is another problem Rohingyas have to deal with, as a formidable presence of Escherichia coli and faecal coliforms in drinking water is evident both at source and household point of use in Rohingya camps [15]. Women are particularly subjected to discrimination in terms of bathing and toilet facilities where a lot of women faced insufficiency of water and privacy issues, and also violence from the men in terms of livelihood conflicts [14] [16]. Collective violence and statelessness are imposing trauma exposure on the Rohingyas which is affecting their mental health as well [12]. Critical dearth of food, scarce housing facilities and poor access to health services are combined causing public health crisis [17]. The Rohingya children suffer from high malnutrition rate which increases the likeliness of outbreaks of infectious diseases in the camps [18]. Polio, tetanus, measles and other diseases are likely to affect as in 2017, a diphtheria outbreak causing $30+$ deaths in the Rohingya camps [19] [20].

In response to the adverse situation the Rohingyas are facing, The Government of Bangladesh, assisted by NGOs including UNHCR made a quick response to control the situation. A crisis response plan was commenced which sought 434 million USD to support the diasporas [21]. Following the crackdown and subsequent influx in 2017, the local aid groups were the first to respond in helping them though they were outnumbered and dominated by the foreign NGOs with time [22] [23]. Foreign donations, especially from Europe are distributed to the NGOs through the central bank and are mostly used in ensuring food supply, constructing shelters, providing medical facilities and other most essential requirements of the refugees in the camps [24]. In the old Rohingya camps, NGOs have long been involved in monitoring food distribution, health, nutrition, primary education, adult education, seed and poultry distribution, vaccination of the children, nonfood item distribution etc. [2]. Since the start of the most recent influx, government of Bangladesh along with more than one hundred national and international NGOs, different bodies of United Nations (UN) and numerous donor agencies have been providing preventive and clinical care and health promotion specially to the pregnant females, newborns, and 
children [25]. Ministry of Health \& Family Welfare of Government of Bangladesh coordinated with Armed Forces Division, UN Bodies, international, national and local NGOs is working to ensure health services to the Rohingyas living in Bangladesh. Health services include intervention activities which provide vaccines, Polio vaccines, cholera vaccine, Vitamin A and also consultation facilities on number of diseases [25]. However, there have been claiming that some of the aid groups were instigating crimes and triggering political agenda in the Rohingya camps, where some of them were reportedly pursuing Rohingyas not to go back to their countries. A number of NGOs, both national and international (unregistered), were banned by Government of Bangladesh [27] [28].

Rohingya refugees are staying in camps of Cox's Bazar in Bangladesh with acute scarcity of basic needs to maintain daily life [2] [6] [14]. As they are totally dependent on donor organizations for their daily needs [14], it is important to understand the present status of the refugees, and stand of the Government of Bangladesh and international communities. Focusing on the described background, this study is conducted to understand the present status of Rohingya refugees in camps of Bangladesh. To fulfill the research interest, available secondary publications including journal articles, newspapers, reports and other online sources were reviewed. Under the study, the stand of Government of Bangladesh and international parties was summarized. Also, this study was conducted to understand the aspects of humanitarian responses, forestry and wild life, disaster risk management, shelter facilities, water sanitation and hygiene (WASH) activities, education, health facilities, adolescent sexual reproductive health, gender-based violence and human trafficking from the perspective of Rohingya refugees in Cox's Bazar camps of Bangladesh. This research manuscript is organized in two sections: 1) present status of Rohinyas, which described the stand of the Government of Bangladesh and international community regarding Rohingya refugees, 2) present status in the camps in Bangladesh shedding light on different aspect of refugees in camps. This research will help international, national and local organizations to take suitable initiatives while providing supports to refugees, as well as international communities and the Government of Bangladesh will get clear idea on current condition of refugees in camps of Bangladesh.

\section{Present Status of Rohingyas: Perception of the Government of Bangladesh and International Communities}

\subsection{Stands of the Government of Bangladesh}

There are more than 500,000 Rohingya refugees living in mainly the makeshift camps in the People's Republic of Bangladesh. A bulk of them is staying unregistered. Bangladesh claims that most of these people who have crossed the borders are living outside of camps have "illegally infiltrated" the country. Most of the time, Bangladesh tried to stop Rohingya refugees from crossing its border [29]. Lately, foreign minister of Bangladesh tagged the violence against the Ro- 
hingya in Myanmar as "a genocide". The country's National Commission for Human Rights conjointly said that it had been considering "pressing for a trial against Myanmar, and against the Myanmar army at an international tribunaP' on charges of mass murder [30].

Since before the recent influx in 2017, Rohingyas were always received by Bangladesh although the country is not a member of 1951 refugee convention. There are two issues that Bangladesh government considers regarding Rohingyas, human rights and national security [31]. Providing refuge to the Rohingyas, Government of Bangladesh's initial focus was to treat the displaced people only for a short term. Dhaka's main focus was to ensure repatriation as soon as possible and not to take into account the multiyear planning of how to treat this huge number of refugees. Sheik Hasina, Bangladesh's Prime Minister visited a Rohingya camp in September 2019 and urged the UN and therefore the international community to pressure Myanmar's government to allow the going back of thousands of Rohingya refugees. She said that Bangladesh would supply the refugee's temporary shelter and aid but Myanmar ought to "take their nationals back" before long [30]. However, this plan of settling the refugees for only a short term has failed as the attempts to return these people to their homeland did not see a feather in the cap as Bangladesh government's recent efforts to repatriate the Rohingyas failed as the refugees did not feel safe to go back [32] [33].

It has been reportedly the fear of Bangladesh authority that publicly acknowledging the uncertainty of the repatriation of the Rohingyas any time soon will worsen the situation and Bangladesh would end up hosting them for eternity. This uncertainty has refrained the Government from ensuring better life conditions and well-planned programs to ensure the future of Rohingyas in terms of making them self-reliant with better education and livelihood opportunities [31]. Instead the government imposed intense restrictions on the movement of Rohingyas and shut down their mobile and internet communication system and several NGO operations [34] [35], where following the failed attempt of repatriation combined with the unrest among the Rohingyas, involvement in crimes like killing of local leaders [28]. Recommendations on building fences, watchtowers and planting security cameras around the Rohingya camps have been given by the Bangladesh Parliamentary Standing Committee to monitor the Rohingyas movement and ensure safety around the camps [31] [32].

The Bangladesh government also had plans to relocate Rohingyas to an island in the Bay of Bengal, which is exposed to severe weather [36]. The plan was brought into light in January, 2018 by the country to relocate many thousands of Rohingya refugees from Myanmar to a distant, flood-prone island that has been regarded "uninhabitable" by experts. According to the plan, authorities would move unregistered Myanmar habitants to "Vashan Char" situated in the Bay of Bengal. The proposal has been criticized by the human rights groups and it was said that the island fully floods throughout monsoon season. The UN also referred the forced relocation as "very complex and controversial" [37].

It is evident that Bangladesh's response towards the refugee crisis has evolved 
from succumbing to human rights appeals to more of a National security crisis management, as amid the recent cases of Rohingyas stranded in the sea, Bangladesh has cleared its stance to not allow anymore Rohingyas into its Border [38] [39].

\subsection{Opinions and Views of International Communities}

The situation of Rohingyas has attracted huge international attention. There have been protests around the cities of India, Pakistan, Thailand, Bangladesh and Malaysia to condemn the atrocities going on with the Rohingyas [40]. The host country's Forest Ministry termed the violence as genocide in a briefing with foreign diplomats [41]. Governments in Southeast Asia, particularly ASEAN countries have mostly maintained their silence on the deteriorating situations of Rohingyas as their hands are tied with the commitment of non-interference [42]. Amnesty International declaimed that the situation of Myanmar in Rakhine is utter practice of crime against humanity on the minorities by the regime [43].

The US state department released a report in 2018, where it blames Myanmar army for the massive scale violence against the Rohingyas amid and the activist group's criticism of US's not so firm stance in terms of the situation they deem as genocide [44]. The term "genocide" is also used in terms of the Rohingyas situation by the Fortify Rights \& United States Holocaust Memorial Museum [45]. The Trump administration has however imposed sanctions over Myanmar military leaders accusing them responsible for extrajudicial killing of Rohingyas and so did Australia, Canada and European Union [42] [46].

The first international lawsuit was filed against Myanmar at the International Court of Justice by Gambia which represented 57 nations of Organization of Islamic Cooperation (OIC) [47]. It was unanimously ruled in by the court that emergency measures had to be taken by Myanmar to protect the Rohingyas and prevent any chances of possible genocide [48]. Besides, International Criminal Court also authorized the start of an investigation to look into the matter [49].

UN reportedly believed that the violence carried out by Myanmar Army was nothing but an attempt to ethnically banish the minority groups with backing of the state [7]. United Nations fact-finding mission suggested the Security Council to enforce arms embargo and sanctions on Myanmar and the county's topmost military officials only to be resisted by countries like China, Russia and others [42]. A report on the involvement of the UN in Rohingya issues commissioned by the UN secretary general documented the organization's systematic failure to curtail the violence against Rohingyas. The humanitarian assistance however has been increased and advocacy groups also accelerated appealing to international communities to impose pressure on Myanmar [42].

\section{Present Status in the Camps in Bangladesh}

\subsection{Humanitarian Responses}

The humanitarian response for Rohingya refugees has been extended with a va- 
riable scale and resources i.e. in the form of formal interventions by government initiatives, international supports, local and national level operations as well as the informal responses such as volunteering, individualized citizen actions, spontaneous helping etc. [22] [50] [51] [52] [53]. Although there is the district-based Refugee Relief and Repatriation Commission (RRRC) established under the Ministry of Disaster Management and Relief (MoDMR), accountability of the humanitarian response generally still lies with the central government not only in terms of coordination but also representation of effort to capacity building. In case of recent Rohingya refugee incident of 2017, there are around 22 departments of Government of Bangladesh and several ministries (MoDMR, MoHFW) coordinated by Armed Force Division, and supported by UN bodies are involved in humanitarian response [26]. However, more than 150 organizations including 13 local and 45 national NGOs are working in the refugee camps, which are strengthening the $12 \mathrm{UN}$ agencies and Red Cross and Red Crescent activities [54] [55]. Rohingya families settled in the camps has been issued food card by the World Food Programme (WFP) with the help of some local partners. The family entitled with a card can receive rice, lintel and oil once or twice a month depending on their family size. According to the allocation by WFP, a small family with 1 to 3 members receives $30 \mathrm{~kg}$ rice, $9 \mathrm{~kg}$ lentils and 3 liters of oil per month whereas a medium size family (4 to 7 members) receives $30 \mathrm{~kg}$ rice, $9 \mathrm{~kg}$ lentils and 3 liters oil, twice in a month, and the family of 8 or more members receives $60 \mathrm{~kg}$ rice, $13.5 \mathrm{~kg}$ lentils and 6 liters of oil, twice a month. Along with this, as WFP is providing them with the monthly fixed ration of rice, lentil and edible oil, they can afford to buy vegetables, salt and spices which are essential for their diet too. E-vouchers were being provided to the refugees with a prospect of covering all by 2019 and recent reports show that the Rohingya children are getting better health and nutrition through these e-vouchers [56] [57]. Again, various NGOs (both national and international) are working in the Rohingya camps by initiating multi-faceted strategies for ensuring refugee safety, security, and proper health care including sexual and reproductive health services, vaccines of MR, Polio, cholera etc., and consultation facilities based on their needs [58] [59] [60]. In addition, Mental Health and Psychological Support (MHPSS) services are programmed in the Rohingya response by number of international organizations to address the mental instability, stress, and anxiety of the refugees [61] [62] [63].

\subsection{Forestry and Wild Life}

Additional population intake by a host territory requires both infrastructural and environmental preparation where influx of Rohingyas barely gave that chance to the land of their habitation in Bangladesh and consequently serious depletion has occurred [61] [64] [65]. In order to accommodate the newly arrived Rohingya refugees, more than 2000 ha of forests have been depleted i.e. 700 tons of forest are essentially disappearing each day in Cox's Bazar [66] [67]. According to UNDP (2018) report, about 793 ha of natural forest land from the 
total forest area of 1502 ha in Ukhia and Teknaf has been encroached by the refugee community in order to build habitation and meet fuel needs. Again, vegetated land is reduced by cutting trees by Rohingya people for timber and selling wood in the local market for money [68] [69]. Around 1200 - 1600 ha (4000 acres) of hilly land in the Teknaf-Ukhia-Himchari area has lost vegetation in want of monthly consumption of about 6800 tons of fuel wood in total and 60 culms of bamboo by a Rohingya family for the construction of temporary shelters [65]. Study conducted by Rashid et al., (2020) has shown a decrease of 1876 ha vegetated land and the increase in land surface temperature (LST) throughout Kutupalong and Balukhali camp from 2017 to 2019 [70]. It is revealed that huge deforestation in the Refugee camp has taken place due to the rapid and unplanned settlements as the existing camp has rapidly expanded into forest areas [71] [72] [73]. Besides, the vigorous green coastal forests of Ukhia and Teknaf Upazilas are the natural habitats for rare wildlife species including birds and Asian elephants e.g. Teknaf Wildlife Sanctuary is an area of 538 species of plants and 613 species of wildlife [53] [74]. The regular route of elephant migration has been completely blocked because of the new setup of camps for Rohingyas [53]. A joint survey by the UNHCR and International Union for Conservation of Nature (IUCN) covering $70 \mathrm{~km}^{2}$ of Cox's Bazar was conducted to prevent deaths of Rohingyas by elephants in the human-elephant conflicts [75]. Elephants and other forest animals are facing food shortages due to the obstacles in free movement on grazing lands [75] [76] [77]. Thus, the environmental dilapidation of forest land is occurring and the overall ecosystem is getting greatly hampered [53]. According to the Bangladesh Forest Department, because of the refugee influx around 7000 hectares (2800 acres) of forest have been heavily damaged-an issue provoking the tensions among the local people. Over 45,000 trees and approximately 700,000 grass cuttings have been planted in just two weeks by Rohingya refugees and also local villagers in Cox's Bazar [78]. The Government claims that they will begin projects to restore the forest cover once the Rohingyas return to Myanmar [79]. Involving Rohingyas immediately in the program of social forestry and systematic management towards restoration of forest might limit the over-utilization of forest, unsustainable logging and unchecked deforestation as well as ensure sustainable use of forest resources [66] [80].

\subsection{Disaster Risk Management}

With the long history of hydrometeorological disaster, the coasts of Bangladesh, especially the district of Cox's Bazar is generally in tropical cyclone risk with high speed winds, extreme rainfall, and storm surge attributes. Moreover, not only the geographical location, lowland and hilly topography of coasts but also the influx of Rohingya refugees makes the region more vulnerable to natural hazard. More than 209,000 Rohingya families with a population of around 900,000 have taken temporary shelter in Cox's Bazar since 2017 [81]. As a result, deforestation and hill cutting have been increased acutely due to the mushrooming of settlement structures, collecting wood fuels, timber, and livelihood for Rohingya 
refugees [65] [66] [68]. However, these facts affected the coastal resilience badly and increased the risk of potential landslides, soil erosion, land degradation, floods, collapsing shelters during monsoon with heavy rain [65] [81] [82] [83]. In this regard, preparation for the cyclone, flood and landslides i.e. planning on response and attempts to mitigate risks continue in collaboration with Government partners as the top priority. As refugees are not permitted to build permanent settlement, upgrading the shelters by concerned authority is a must to go on [84] [85] [86] [87]. A number of 169,866 households were provided with tie down kits that allows the houses to resist wind up to $40 \mathrm{~km} / \mathrm{hr}$. Midterm and transitional shelters which can resist air speed of 50 and $80+\mathrm{km} / \mathrm{hr}$., respectively are provided to 3400 households. In September 2018, relocation of 43,640 refugees to newly developed sites or safer places within their camps have been carried out to mitigate flood and landslide risks and also risks generating from new arrivals. 26,177 of this population were still in the extreme landslide risks where safe passage for emergency evacuations and management through proper risk prediction and assessment is a dire urgency now [81] [88]. Disaster risk reduction (DRR) activities like stabilization of slope, reinforcement of WFP assistance, strengthening the shelters for cyclone preparedness, arrangement of emergency response training, provision of emergency response kits to the community, addressing and promoting health issues are going on. Bamboo bridges are also being constructed by WFP with IOM and other partners to improve access to the camps for refugees [50] [89].

\subsection{Shelter Facilities}

Facilitating shelter to the Rohingyas started with the admission and safe living arrangement on the South-eastern border of Bangladesh i.e. the Upazila of Cox's Bazar Sadar, Ukhia and Teknaf of the district of Cox's Bazar upon the sudden movement of a large number of fleeing refugees (i.e. 700,000 to more than 950,000) from Myanmar [6] [66] [90]. As there was no permanent structure of settlement for the huge number of refugees, they were provided shelter in the local school and college buildings where migrant size is the big challenge for the GoB [65]. The Rohingya people built their makeshift settlements of the multiple clusters i.e. congested camps by clearing both natural forest land and plantation land as well as on the hilly terrain to avoid flooding [70]. On top of that, the temporary shelters are fragilely constructed with an extreme heat and no ventilator, and these are also vulnerable to the regular natural calamities of coasts due to the usage of plastic sheets, tarpaulin, mud, brick and bamboos as the building materials [14]. Furthermore, all the physical structures like road, houses, bridge are built temporarily and many camps cannot get electricity. Nevertheless, many changes are seen in the infrastructure level to provide accommodation facilities and access to transport and communication [79]. However, shelters are kept on being upgraded in the camps and settlements, with the support of extra tarps, rope, bamboo and wire to 212,360 households, which is $100 \%$ of the households which were targeted. Tie-down kits were also provided to 160,637 households 
(76\% of the target). All of these were supplied to them to serve the purpose of preparing them for upcoming cyclones. Relocation of 40,296 refugees have been done by August, 2018 to the newly developed sites to lower the risk of landslide and flood crises and also the hazards which may create from new arrivals where 24,401 of these were to mitigate landslide risks. Due to ongoing risk of high winds and heavy rains, safe space for emergency evacuation is urgently needed. Severely congested camp conditions may create long term negative consequences, that more land for sustainable relocation is an urgent need [91].

\subsection{WASH Activities}

The overcrowded Rohingya camps terrifically lack clean and safe water supply, proper sanitation, hygiene and waste management facilities [92] [93]. Water contamination is the problem that Rohingyas have to deal with as a formidable presence of Escherichia coli and faecal coliforms in drinking water is evident both at source and household point-of-use in Rohingya camps [15]. Furthermore, intense rain and associated inundation during monsoon could demolish existing latrines and tube-wells resulting in contamination of groundwater from flooded latrines and washing sewage into drinking water supplies. This acute condition might cause the threat of common water-borne disease outbreaks e.g. cholera, diarrhea, hepatitis etc. in the congested camps [92] [93] [94] [95] [96]. However, women are particularly subjected to discrimination in terms of bathing and toilet facilities where a lot of women faced insufficiency of water, safety and privacy issues, increasing risk of sexual abuse and harassment, and also violence from the men in terms of livelihood conflicts [14] [16]. ReliefWeb (2019) reported that $23 \%$ girls and $57 \%$ women had the feeling of insecurity while simply using latrines and it hindered the safe sanitation access [87]. Under the coordination of WASH focal agency, IOM, UNHCR and UNICEF, for all WASH aspects, DPHE works UN Agency (UNICEF) and NGOs (Action Against Hunger, OXFAM, BRAC) to coordinate, oversight, monitor and plan on behalf of GoB for the humanitarian response [98] [99]. As the responses in WASH sector, number of series collaboration and synergies among humanitarian community, development partners and donors, and GoB (e.g. Joint Response Plan, WASH Sector, EMRCRP-Emergency Multi-Sector Rohingya Crisis Response Project, EAPWSS-Emergency Assistant Project for Water Supply and Sanitation at Ukhia and Teknaf Upazillas in Cox's Bazar, BD) had been initiated to provide safe water supply, latrines, faecal sludge management facilities uninterruptedly [100]. Besides, various INGOs are taking programs to improve sanitation services addressing the needs of Rohingya refugees in Cox's Bazar contributing to transition towards longer-term solutions [101].

\subsection{Education}

Ensuring the right to education for the Rohingya refugees was set out as a vision for the stakeholders especially for the host country through including required arrangement as per the UNHCR's "Refugee Education 2030" [102]. However, 
according to UNHCR, more than half of the (55\%) Rohingya refugee in Bangladesh is under the age of 18 . This is a demographic condition that compelled Bangladesh Government to specially emphasis on the education service with the assistance of humanitarian stakeholders e.g. UN bodies, INGOs, donors etc. [91]. In this regard, a number of learning centres were established on temporary basis where early grade lessons on the Burmese language, mathematics and English are being taught to the learners [103]. More than 2000 learning centres were built in the refugee camps but there was no access to formal education that a tailor-made Learning Competency Framework curriculum jointly developed by UNICEF and other partner organizations [104]. Also, Karin et al., (2020) studied that there was an access to education in mainstream primary schools (up to Class 8 ) in the registered camps only [14]. Around $85 \%$ of girls were found to go to the temporary learning centres where rest went to the Madrasah. In these informal schools, a customized curriculum was used for the Rohingya children of under 15 as per the permission granted by GoB to UNICEF where 70\% of non-formal schools were under the operation of NGOs [104] [105]. Again, a number of 118 learning centers were made in March 2019 which measured to be benefitting about 80,000 Rohingya adolescents including $49 \%$ of girls [100]. An estimation of UNICEF revealed that 300,000 children had access to education leaving $16 \%$ of children (ages 3 - 14) and $81 \%$ (ages 15 - 24) without access to education [99]. Among the 117,000 youngsters in need of the access to the quality education or life skills training, only less than 2,000 were able to manage in getting them [91] [105]. One of the major concerns here is the inadequate learning facilities for the adolescents and youth between 15 to 24 years of age i.e. having no access to this aged group with an alarming percentage of 83 as per the 2020 JRP [105] [106]. The study conducted by Bakali \& Wasty (2020) showed the educational realities of the Rohingyas in terms of limitation and opportunities to implementation of education programming in the camps. Several potential factors e.g. priority in comparison to essential needs and services, status of functional infrastructure, political influence, power structure and program curriculum design and standard etc. were found to be involved in executing education and learning program for the Rohingya community [107] [108].

\subsection{Health Facilities}

According to the recent assessment by the Ministry of Health and Family welfare of over 100 heath facilities, medical waste management is a key gap in the camps. In some specialty areas, critical health gaps also remain-including the local communities in the premises of the camps-such as surgical services, availability of health services for $24 / 7$ and clinical mental health services. Heavy rainfall increases the risks of water and carrier-borne diseases [91].

Furthermore, 115 health posts have been established in the last year, each of them covers around 7700 people. Besides, 60 primary health care facilities and 11 secondary care facilities are covering 20,000 and 115,000 people respectively. WHO with the Ministry of Health and Family Welfare synchronized the emer- 
gency health care services provided by nearly 107 partners in the region? Nearly 175 tons of medicines have been delivered to the camps by WHO. However, Rohingya population doesn't seem willing to utilize the access to sexual and reproductive health services, as $70 \%$ of the birth is still taking place outside of the health facilities [91].

Aiming to meet the reproductive health needs of around 22,000 pregnant women among an estimated 646,000 women in Rohingya camps, a Minimum Initial Service Package (MISP) has been implored where United Nations Population Fund (UNFPA) serves the leading role. Manifold setbacks hampers women's access to reproductive health facilities in the Rohingya camps while cost being the major barrier [109]. Presence of 11 Basic Emergency Obstetric and Newborn Care (BEmONC) facilities would perhaps just meet the standard if not for tough access to these because of crowd, lack of roads and cumbersome terrain [110]. Cesarean deliveries are available in some hospitals which are just outside Kutapalong camp while a government operated health complex in Ukhia which also provides the cesarian facilities are 10 minutes away [111]. However, it takes the pregnant women more than couple of hours to reach the district hospitals of Cox's Bazar for such facilities. Despite there is a facility which offers Comprehensive Emergency Obstetric and Newborn Care (CEmONC), it is not open for 24/7.

As the refugees are recurrently undergoing exposure of violence, stress resultant from leaving ancestral homes and properties behind and tensions in the refugee settings because of insolvency, living conditions, different culture and language and constant feeling of uncertainty regarding future; mental health is expected to be a common scenario among them [112] [113] [114]. A study carried out by Khan et al. (2019) focused on Rohingya children exposed to high risk of mental health problems [115]. Also, UNHCR geared up its effort to integrate Mental Health and Psychological support (MHPSS) in 2018 [116]. The MSPSS strategy was based on strengthening community-based psychosocial support, introducing scalable psychological interventions and ensuring that mental health services become accessible in the primary health care facilities for the Rohingyas which were under the jurisdiction of UNHCR and its partners [117] [118] [119].

As a response to diphtheria outbreak in the Kutupalong camp the World Health Organization (WHO) deployed its Global Outbreak Alert and Response Network (GOARN) team which consisted of epidemiologists, vaccine specialists and technical experts [120]. The main focus of the GOARN team, while working with Bangladesh Ministry of Health and Family Welfare (MoHFW) and other health agencies, was to deliver technical assistance for building capacity for better prevention and control of outbreaks [121]. Other infectious epidemic prone diseases and health complicacies were also detected and summarized using the Early Warning, Alert and Response System (EWARS), which is basically a mobile application used for detection, notification and response in emergency circumstances [122]. The GOARN team contributed in establishment and moni- 
toring of EWARS for diphtheria and other detected infectious diseases, coordination of contact tracing, establishment of local lab capacity for diphtheria and other selected diseases and providing training and support in preventing infection and potential health cases and also proving control assessment [123].

\subsection{Adolescent Sexual Reproductive Health}

The Rohingya population is about 1 million now after the last recent influx since August 2017, 52\% of which is comprised of women and girls and children also consist 55 - 60 numbers. The Sexual Reproductive Health (SRH) consequences among the adolescent girls are yet to be examined, but it is already possible to guess its extent as the likelihood of death of women and children is 14 times higher than the men. According to the latest data, $75 \%$ of juvenile girls have expressed the need of menstrual hygiene management in the Rohingya Camp. Their need of menstrual hygiene remains mostly unmet due to the lack of water, lack of privacy in WASH facilities. For example, there are not separate bathing spaces for different genders in the 75 to 80 facilities and that is a serious issue for the women. The situation is most unpleasant in the rainy season, particularly reusable clothes take longer to dry [91] [124].

Reproductive tract infection (RTI) is common for $75 \%$ of all women and girls in the camps, which is logical as the camps have scarce resources, limited spaces and WASH facilities. Besides, what the adolescent girls have to say is not reflected into the existing humanitarian programs, planning and assessment and also not in the Adolescent Sexual Reproductive Health (ASRH) needs, information and services. Thus, it understates their necessities to include more adolescent needs and choice especially when it is related to their own body and health [91] [124].

Executing comprehensive Sexual and Reproductive Health (SRH) services is subjected to specific challenges in a refugee camp because of their vulnerability and transitions and absence of clearness in traditional beliefs and cultures [125]. Although, quite a few number of partner organizations in Rohingya refugee camps of Cox's Bazar are providing minimum initial service package of SRH, access to inclusive reproductive, maternal and newborn health services remains a challenge because of unevenness in the quality of services and inconstancies in application of the minimum package of health services under operation sanctioned by different authorities [126] [127]. WHO aims to deliver integrated comprehensive services to encounter the instantaneous SRH needs of vulnerable women and adolescent girls of acutely vulnerable Rohingya people [126] [127] [128].

In terms of sexual and reproductive health awareness, many female members of refugee camp believed the contraception as religiously forbidden and many others assumed that it causes infertility [128]. The refugee women reportedly had fair knowledge of pregnancy but insufficient knowledge of sexual and reproductive health. The survey of ISCG (2018c) found that health service providers tried to provide a little knowledge regarding contraception to the adolescents 
and they were hesitant in sharing any knowledge of pregnancy and family plantings with them [91]. In cases of adolescent pregnancy, they just refer them to hospitals. They try to explain what might happen if one goes into an intimate relationship, but they do not try to teach how to prevent pregnancy. There is reportedly crisis of teachers and insufficient education opportunities for the adolescents of 1 - 24 years old in the Rohingya camps as well [91].

\subsection{Gender Based Violence}

According to the United Nations Office for the Coordination of the Humanitarian Affairs (UNOCHA), hundreds of cases of gender-based violence continue to be reported every week. Karim (2018) stated that,

"We get a lot of cases where women are badly beaten by their husband. As the men don't have much to do in the camp, some take out their frustration on the women over seemingly matters". [79]

A survey among 300 girls in the camps was conducted by Plan international; found out that one of the biggest problems that adolescent girls face is freedom of movement in the camps. Social cultural factors and security concerns keep the older girls confined to their households [79]. Challenges are faced by women and girls of camps in terms of safety, information access and receiving services and discrimination in decision-making. Restrictions on freedom of movement, cultural and social hurdles, illiteracy and abridged community and legal protections make women and girls more susceptible to GBV [129].

For Gender Based Violence (GBV) case management, about 78 safe entry points have been set up, including 52 safe spaces for women and girls (SSWG). Since March 2018, the GBV response and prevention interventions have reached at least 345,489 persons, approximately $30 \%$ of these are girls. More than 187,318 females (108,732 women, 78,586 girls) have been reached through GBV prevention programs including engagement and empowerment interventions for women and girls. In 28 refugee sites in Ukhia and Teknaf Upazilas, comprehensive GBV service referral pathways are established [91].

Gender, being in exile, ethnic association etc. makes the Rohingya women subjected to threat from offenders of not only Rohingya men but also men from the host communities. One of many reasons behind the nonstop assaults on the women in the refugee camps is the collapse of family and social setting [60]. Also, ReliefWeb (2017) mentioned myriads of risks that the children, adolescents and women in both the Rohingya and host communities are exposed to [130]. These include extreme violence, exploitation and abuse like sexual harassment, child marriage, child laboring and human trafficking. Rohingya children are reportedly subjected to human trafficking for sexual purposes around Cox Bazar and across Bangladesh from the refugee camps [131]. An investigation on human trafficking reported the rescue of 23 Rohingya girls being trafficked to Malaysia from the camps in Bangladesh. The specialist's claim that only a small percentage of the victims are being detected [132]. Almost 6000 Rohingya child- 
ren are identified vulnerable to sex trading, child marriage and other sexual abuses [96]. Women and girls also face barriers in accessing health services [60]. It was reported that $1 / 5$ th of girls and $57 \%$ t of women felt insecure in just using latrine [96].

Urgency is manifested to create safe spaces and take foresighted long-term actions against Gender Based Violence (GBV) by numerous NGOs working in the Rohingya refugee camps of Bangladesh [133]. The GBV sub sector coordination structure was established in Cox's Bazar in May 2017. It was later strengthened and extended in August of the same year to meet the needs of the huge number of Rohingya refugees' influxes in Bangladesh [134]. The GBV Sub-Sector in Cox's Bazar is commanded by the United Nations Population Fund [135]. It consists of 28+ standing member organizations like the United Nations, International and local NGOs and government agencies working within the Rohingya refugee camps and the adjacent affected host community areas [60]. Hope Foundation, a Bangladeshi NGO and a member of this GBV sector has trained more than a hundred health professionals to handle the cases of GBV. These trainings are to toughen the local capacity to combat and respond the ongoing sexual and gender-based violence within the camps and the host communities as well [136].

\subsection{Human Trafficking}

The lead agency working on to combat human trafficking in Cox's Bazar is the International Organization for Migration (IOM). The agency is scaling up its activities to counter trafficking which include protection, prevention, psychological and material aid to survivors, and legal support to victims. Data is limited due to the concealed nature of the crime and common lack of enthusiasm of victims to share their experiences because of stigma and fear of vengeance. Nevertheless, the pictures and identified cases provide a lead to identify main forms of trafficking activities occurring against Rohingya refugees in Cox's Bazar [78].

Cases of trafficking reported by Rohingya refugees who have lived in Bangladesh for years, who arrived within the last few years, and who have recently arrived since August 2017 are identified by IOM. A number of people were targeted by traffickers after being in the country for just a few weeks. In the temporary settlements, desperate men, women and children are tempted with fake offers of paid work in various industries, including fishing, small commerce, begging and domestic work in case of women [137].

Bangladeshi law enforcement agencies e.g. Police, RAB, Ansar, Bangladesh Army and all intelligence agencies have been working to ensure highest security for Rohingyas. RAB and police have set up quite a few camps in Ukhiya and Teknaf for Rohingyas. Besides, government is in the process of deploying three armed police battalion in the camps which will expectantly heighten the security measures in the Refugee camps [138].

Rohingyas also become the subjects of smuggling and migration to Malaysia. Registered Rohingya refugees who are young and living in the two official camps 
see no future for them. While the unregistered Rohingyas are in much worse condition as they have no legal status, no legal protection, and have only limited access to basic facilities. Three categories of Rohingyas are leaving for Malaysia: those who come directly from Myanmar and use Bangladesh as a transit point, those who are already living legally in Bangladesh, and those who are living illegally in the country [79]. Rohingya families pass their days in intense insecurity, as disappearance of Rohingya women and children are common instances in the camps. Young female members of many families are locked all the day for protection from the traffickers and their agents [55].

Another wave of human trafficking found its way in the end of 2018 and reached its peak by the beginning of 2019. Reports articulate about the arrest and detention of Rohingya men by the police of northern Malaysia who were able to reach the shore while hundreds of them were still stuck in the sea [139]. Report also says of Rohingya men and women trying to enter and getting detained in Mizoram state of India [140]. A group of Rohingya people who settled in India around 2013 were intercepted in Hyderabad airport of India who tried to take flight to Malaysia with fake Indian passports. Apparently, they had help of a ring with the skills of forging fake passports and papers [141]. However, not all the refugees can even reach the destination regardless of they can settle or not after reaching. There also reports of coning where men and women were deceived and were taken to another Island of Bangladesh while they actually paid for the passage to other countries [142]. Analysis and monitoring estimates that this trafficking syndicate is composed of parties spread across Bangladesh, Myanmar, Malaysia and Thailand [143].

\section{Conclusion}

Though Bangladesh has been hosting almost a million refugees, the country has always rejected any possibility of the stay of the Rohingyas being perpetual. Statements in the later part of 2019, from the leaderships of Bangladesh indicate that the country is deeming the Rohingyas as national security threats rather than that of an exploited community. The international community however criticized the decision of transferring the Rohingyas to a disaster-prone Island. Humanitarian assistance and advocacy to increase pressure on Myanmar have been continued. However, the efforts taken to confront epidemic breakout in the camps also declaim appreciation. Adolescent health, nevertheless, is still open to various social, cultural, religious challenges. In particular, awareness of young girls about certain reproductive health issues is being tabooed there. GBV is another important aspect of the refugee life which has been focused on by the national and international bodies. Living with the uncertainty, Rohingya refugees are facing enormous crisis in relation to basic needs and other life sustaining facilities to overcome difficulties. Although an extended humanitarian response in a variable scale has been initiated, Rohingyas are suffering from limitations of resources and coordination is required for proper implementation of 
emerging opportunities and planning. Involving a large number of refugees systematically in various social and joint programs such as restoration of natural resources, forestland as well as the Disaster risk reduction (DRR) activities towards sustainable management is a demanding need at present. The research was conducted based on available secondary literature and no field level assessment was done, which is a limitation of this study. Further study may be conducted on specific issues like health, education, food etc. regarding Rohingya refugees based on field level surveys or expert opinions.

\section{Conflicts of Interest}

The authors declare no conflicts of interest regarding the publication of this paper.

\section{References}

[1] Ekeh, C. and Smith, M. (2007) Minorities in Burma. Minor. Rights Gr. Int. Brief., 5.

[2] Holland, M.S.F., Fronti, S. and March, H. (2002) 10 Years for the Rohingya Refugees in Bangladesh: Past, Present and Future. Médecins Sans Frontières, 1-45.

[3] Shuvo, S.H. (2018) Rohingya Crisis in 2017-2018: Geo-Politics and the International Reaction. International Journal of Natural and Social Sciences, 5, 2017-2018.

[4] Petersen, H. and Ahmed, K. (2018) Start of Rainy Season Exposes Risks for Rohingya Refugees in Bangladesh. The Guardian.

[5] UNHCR (2018) Operational Update: Bangladesh (27 December 2017-7 January 2018).

[6] Zaman, K.T., Hasan, W.U., Bazlul, L., Motahar, T. and Ahmed, N. (2019) Exploring Challenges and Solution Approaches Regarding Wellbeing of Female Rohingya Community in Bangladesh. Proceedings/ TENCON, Vol. 2019, 361-366. https://doi.org/10.1109/TENCON.2019.8929413

[7] Osborne, S. (2017) Burmese Government May Be Trying to "Expel” All Rohingya Muslims, UN Special Rapporteur Warns. The Independent.

[8] Quackenbush, C. (2017) Amnesty Accuses Myanmar of Apartheid against Rohingya, TiIME.

[9] Devi, H.O. (2019) The Vulnerability of the Rohingya Refugees, Café Dissensus.

[10] Knight, K. (2013) How Bangladesh Aid Restrictions Impact Rohingyas. The New Humanitarian.

[11] WFP (2012) World Food Program, Government of the People's Republic of Bangladesh, and United Nations High Commissioner for Refugees (UNHCR), Joint Assessment Mission: Myanmar Refugees in Cox's Bazar District, Bangladesh.

[12] Riley, A., Varner, A., Ventevogel, P., Hasan, M.M.T. and Welton-Mitchell, C. (2017) Daily Stressors, Trauma Exposure, and Mental Health among Stateless Rohingya Refugees in Bangladesh. Transcultural Psychiatry, 54, 304-331. https://doi.org/10.1177/1363461517705571

[13] Kiragu, T.M.E. and Rosi, A.L. (2011) States of Denial: A Review of UNHCR's Response to the Protracted Situation of Stateless Rohingya Refugees in Bangladesh.

[14] Karin, S., Chowdhury, M.A. and Shamim, I. (2020) Status of Rohingya Refugees in Bangladesh: A Comparative Study with Emphasis on Aspects of Women and Girls 
in Camps of Kutupalong, Cox's Bazar, Bangladesh. OALib, 7, 1-4. https://doi.org/10.4236/oalib.1105831

[15] Mahmud, Z.H. (2019) Occurrence of Escherichia coli and Faecal Coliforms in Drinking Water at Source and Household Point-of-Use in Rohingya Camps, Bangladesh. Gut Pathogens, 11, 52. https://doi.org/10.1186/s13099-019-0333-6

[16] Akhter, S.A. and Kusakabe, K. (2014) Gender-Based Violence among Documented Rohingya Refugees in Bangladesh. Indian Journal of Gender Studies, 21, 225-246. https://doi.org/10.1177/0971521514525088

[17] Pocock, N.S., Mahmood, S.S., Zimmerman, C. and Orcutt, M. (2017) Imminent Health Crises among the Rohingya People of Myanmar. BMJ Clinical Research, 359, j5210. https://doi.org/10.1136/bmj.j5210

[18] UNICEF (2017) Malnutrition Rates among Rohingya Refugee Children in Bangladesh Appear to Be at Least Double Earlier Estimates.

[19] WHO (2017) Diphtheria Outbreak Response Update, Geneva.

[20] UNICEF (2018) Bangladesh: Humanitarian Situation Report No. 23 (Rohingya Influx), 18 February 2018 Bangladesh. ReliefWeb.

[21] UNHCR (2017) Supplementary Appeal-Myanmar Refugee Emergency Response in Bangladesh.

[22] Surge, H. (2018) Bangladesh: Local Aid Groups Getting Left behind. Humansurge, Blog.

[23] Ahmed, K. (2019) Local Aid Groups Want More of a Say in the Rohingya Refugee Response. The New Humanitarian, 1-9.

[24] Islam, M.Z. (2019) NGO Aid Rises on Rohingya Crisis. The Daily Star.

[25] UNICEF (2018) Bangladesh: Humanitarian Situation Report No. 45 (Rohingya Influx), 27 November to 10 December 2018-Bangladesh. ReliefWeb.

[26] MOHFW (2020) Forcibly Displaced Myanmar National to Bangladesh.

[27] The Daily Star (2019) NGOs Working in Rohingya Camps to Face Action If Violate Terms: FM.

[28] Shuvo, S.S. (2019) NGO Activities in Rohingya Camps. The Daily Observer.

[29] Guhathakurta, M. (2017) Understanding Violence, Strategising Protection: Perspectives from Rohingya Refugees in Bangladesh. Asian Journal of Social Science, 45, 639-665. https://doi.org/10.1163/15685314-04506003

[30] Rubayet, R. (2017) Myanmar: Who Are the Rohingyas? https://www.academia.edu/34837307/Myanmar_Who_are_the_Rohingya

[31] Imran, N.A. and Mian, H.F. (2014) The Rohingya Refugees in Bangladesh: A Vulnerable Group in Law and Policy. Journal of Studies in Social Sciences, 8, 226-253.

[32] HRW (2019) Bangladesh: Clampdown on Rohingya Refugees. Human Rights Watch. https://www.hrw.org/news/2019/09/07/bangladesh-clampdown-rohingya-refugees

[33] CGD (2019) Designing a Medium-Term Response to the Rohingya Refugee Crisis: Ideas for Bangladesh, the International Community, and the Private Sector. Center for Global Development, Washington DC.

https://reliefweb.int/report/bangladesh/designing-medium-term-response-rohingya -refugee-crisis-ideas-bangladesh

[34] Bdnews24.com (2019) Govt Curbs 3G, 4G Mobile Services at Rohingya Camps, Surrounding Areas.

[35] Beech, H. (2019) A Million Refugees May Soon Lose Their Line to the Outside 
World. The New York Times.

https://www.nytimes.com/2019/09/05/world/asia/rohingya-phone-ban.html

[36] ICG (2019) A Sustainable Policy for Rohingya Refugees in Bangladesh. Brussels.

[37] Zaman, M. (2018) Rohingyas Need Protection, Not Relocation to Bashan Char. The Daily Star.

[38] UNB (2019) Rohingyas Threat to National, Regional Security: PM. The Daily Star. https://www.thedailystar.net/country/pm-sheikh-hasina-says-rohingyas-threat-nati onal-regional-security-1825600

[39] IANS (2020) "Not a Single Rohingya Will Be Allowed to Enter": After Malaysia, Bangladesh Bars Entry of Rohingyas.

https://swarajyamag.com/insta/not-a-single-rohingya-will-be-allowed-to-enter-after -malaysia-bangladesh-bars-entry-of-rohingyas

[40] Khan, S. (2016) Burma’s Aung San Suu Kyi Accused of "Legitimizing Genocide of Rohingya Muslims".

https://www.independent.co.uk/news/world/asia/rohingya-muslims-burma-myanm ar-aung-san-suu-kyi-legitimising-genocide-a7439151.html

[41] Al-Jazeera (2017) Bangladesh FM: Violence against Rohingya Is Genocide.

[42] Albert, E. and Maizland, L. (2020) The Rohingya Crisis. https://www.cfr.org/backgrounder/rohingya-crisis

[43] Quackenbush, C. (2017) Rakhine State Is a Crime Scene. Amnesty International Accuses Myanmar of Apartheid.

https://time.com/5031278/myanmar-rohingya-amnesty-international-apartheid

[44] Gallo, W. (2018) Activists: US Stance on Rohingya Not Strong Enough.

https://www.voanews.com/east-asia-pacific/activists-us-stance-rohingya-not-strong -enough

[45] FR (2017) “They Tried to Kill Us All” Atrocity Crimes against Rohingya Muslims in Rakhine State, Myanmar.

[46] Brunnstrom, L.W.D. (2019) U.S. Imposes Sanctions on Myanmar Military Leaders over Rohingya Abuses.

https://www.reuters.com/article/us-usa-myanmar/u-s-imposes-sanctions-on-myan mar-military-commander-over-rohingya-abuses-idUSKCN1UB2QM

[47] ICJ (2019) Application Instituting Proceedings and Request for Provisional Measures.

[48] ICJ (2020) Application of the Convention on the Prevention and Punishment of the Crime of Genocide (The Gambia v. Myanmar).

[49] ICC (2019) ICC Judges Authorise Opening of an Investigation into the Situation in Bangladesh/Myanmar.

[50] Ahmad, M.S. and Rahman, N. (2019) Emergency Response Training and Provision of Emergency Response Kits to Rohingya Community Leaders: An Approach to Local Disaster Risk Reduction and Community Resilience. Emergency Medicine Journal, 36, 255-256. https://doi.org/10.1136/emermed-2018-207843

[51] HPN (2018) Rohingya Refugees in Bangladesh: The Humanitarian Response. The Humanitarian Practice Network at Overseas Development Institute, London.

[52] Lewa, C. (2009) North Arakan: An Open Prison for the Rohingya in Burma. Forced Migration Review, No. 32, 11.

[53] Rahman, M.D. (2019) Rohingya Refugee and Humanitarian Crisis: Synergies within Bangladesh Government and Humanitarian Community (Case Study: WASH for 
Rohingya Refugees). TVVR-19/5007.

[54] Khan, M. (2018) The Fight for Rohingya Rights, Star Weekend. The Daily Star.

[55] Wake, C. and Bryant, J. (2018) Capacity and Complementarity in the Rohingya Response in Bangladesh. ODI, London. http://www.odi.org/publications/11251-capacity-and

[56] Chandan, M.S.K. (2018) The Business of Survival. The Daily Star, 02-Sep-2018.

[57] Hoddinott, J., Dorosh, P., Filipski, M., Rosenbach, G. and Tiburcio, E. (2020) Food Transfers, Electronic Food Vouchers and Child Nutritional Status among Rohingya Children Living in Bangladesh. PLOS ONE, 15, e0230457. https://doi.org/10.1371/journal.pone.0230457

[58] Singh, N.S., Aryasinghe, S., Smith, J., Khosla, R., Say, L. and Blanchet, K. (2018) A Long Way to Go: A Systematic Review to Assess the Utilisation of Sexual and Reproductive Health Services during Humanitarian Crises. BMJ Global Health, 3, e000682. https://doi.org/10.1136/bmjgh-2017-000682

[59] Hossain, M.M., Sultana, A., Mazumder, H. and Murshid, M.E. (2018) Sexually Transmitted Infections among Rohingya Refugees in Bangladesh. The Lancet HIV, 5, e342. https://doi.org/10.1016/S2352-3018(18)30140-1

[60] Goodman, A. and Mahmood, I. (2019) The Rohingya Refugee Crisis of Bangladesh: Gender Based Violence and the Humanitarian Response. Open Journal of Political Science, 9, 490-501. https://doi.org/10.4236/ojps.2019.93027

[61] Harrison, S., Ssimbwa, A., Elshazly, M., Mahmuda, M. and Rebolledo, O.A. (2019) How to Conduct a Mental Health and Psychosocial Support Situational Analysis in a Refugee-Based Emergency Context: A Case Study Example from Cox's Bazar, Bangladesh. Intervention, 17, 122. https://doi.org/10.4103/INTV.INTV_42_19

[62] Borja Jr., A., Khondaker, R., Durant, J. and Ochoa, B. (2019) Child-Centred, Cross-Sectoral Mental Health and Psychosocial Support Interventions in the Rohingya Response: A Field Report by Save the Children. Intervention, 17, 231. https://doi.org/10.4103/INTV.INTV_17_19

[63] Tay, A.K. (2019) The Culture, Mental Health and Psychosocial Wellbeing of Rohingya Refugees: A Systematic Review. Epidemiology and Psychiatric Sciences, 28, 489-494. https://doi.org/10.1017/S2045796019000192

[64] Hussain, A. (2018) Rohingya Influx, a Threat to Forest Resources. Dhaka Tribune.

[65] Yasmin, L. and Akther, S. (2020) The Locals and the Rohingyas: Trapped with an Uncertain Future. Asian Journal of Comparative Politics, 5, 104-120. https://doi.org/10.1177/2057891119865021

[66] Mukul, S.A., et al. (2019) Rohingya Refugees and the Environment. Science, 364, 138. https://doi.org/10.1126/science.aaw9474

[67] UNDP (2018) Environmental Impacts of Rohingya Influx: A Multifaceted Problem Requires Multifaceted Responses. United Nations Development Programme. https://www.bd.undp.org/content/bangladesh/en/home/presscenter/pressreleases/2 018/09/18/Environmental_impacts_of_Rohingya_influx.html

[68] Tani, M. and Rahman, M.A. (2018) Deforestation in the Teknaf Peninsula of Bangladesh. https://doi.org/10.1007/978-981-10-5475-4

[69] Pau, P.K. (2019) Indo-Burma Frontier and the Making of the Chin Hills: Empire and Resistance. Routledge, London. https://doi.org/10.4324/9780429324703

[70] Rashid, K.J., Hoque, M.A., Esha, T.A., Rahman, M.A. and Paul, A. (2020) Spatiotemporal Changes of Vegetation and Land Surface Temperature in the Refugee Camps and Its Surrounding Areas of Bangladesh after the Rohingya Influx from 
Myanmar. Environment, Development and Sustainability. https://doi.org/10.1007/s10668-020-00733-X

[71] UNHCR (2019) Rohingya Emergency.

[72] GOB (2019) Environmental and Social Management Framework. Emergency Multi-Sector Rohingya Crisis Response Project (EMRCRP), Dhaka.

[73] Kolovos, P. (2018) One Year on, Rohingya Refugees Live in Dire Camps, Facing an Uncertain Future and Legal Limbo.

https://www.msf.org/one-year-rohingya-refugees-live-dire-camps-facing-uncertainfuture-and-legal-limbo

[74] Yasmin, L. and Sayeda, A. (2019) Piloting a Shared Source Water Treatment Intervention among Elementary Schools in Bangladesh. The American Journal of Tropical Medicine and Hygiene, 101, 984-993. https://doi.org/10.4269/ajtmh.18-0984

[75] Star, T.D. (2018) Elephant Attack at Kutupalong Rohingya Camp UNHCR, IUCN Join Hands to Safeguard Refugees. Dhaka, Bangladesh, 04 Mar. 2018.

[76] Rahman, M. (2019) Rohingya Refugee Crisis and Human vs. Elephant (Elephas maximus) Conflicts in Cox's Bazar District of Bangladesh. Journal of Wildlife and Biodiversity, 3, 10-21.

[77] IUCN (2018) Survey Report on Elephant Movement, Human-Elephant Conflict Situation, and Possible Intervention Sites in and around Kutupalong Camp, Cox's Bazar. International Union for Conservation of Nature, Dhaka.

[78] IOM (2018) IOM, FAO Re-Plant Bangladesh Forest to Repair Environmental Damage Caused by Refugee Influx. International Organization for Migration. https://www.iom.int/news/iom-fao-re-plant-bangladesh-forest-repair-environment al

[79] Karim, N. (2018) One Year of Rohingya Exodus from an Elephant Jungle to the World's Largest Camp. The Daily Star, September 2, 2018.

[80] Tallis, H., Huang, C., Herbohn, J.L., Holl, K., Mukul, S.A. and Morshed, K. (2019) Steps toward Forest Landscape Restoration in the Context of the Rohingya Influx: Creating Opportunities to Advance Environmental, Humanitarian, and Development Progress in Bangladesh. CGD Policy Pap. 148

[81] Alam, A., Sammonds, P. and Ahmed, B. (2020) Cyclone Risk Assessment of the Cox's Bazar District and Rohingya Refugee Camps in Southeast Bangladesh. Science of the Total Environment, 704, Article ID: 135360. https://doi.org/10.1016/j.scitotenv.2019.135360

[82] Crew, J. (2018) Fears for Rohingya as Refugee Camps Battered by Cyclones and Monsoons.

[83] JRP (2018) JRP for Rohingya Humanitarian Crisis. Dhaka.

[84] BBC (2018) Rohingya Refugees Unprepared as Monsoon Rains, Flooding and Landslides Continue.

[85] IOM (2018) Over 1,000 New Shelters Built for Rohingya Refugees Threatened by Landslides.

[86] Beaubien, J. (2018) Forced to Flee Myanmar, Rohingya Refugees Face Monsoon Landslides in Bangladesh.

[87] Cousins, S. (2018) People Will Die as Monsoon Approaches Rohingya Refugee Camps in Bangladesh. BMJ, 361, k2040. https://doi.org/10.1136/bmj.k2040

[88] Ahmed, N., Firoze, A. and Rahman, R.M. (2020) Machine Learning for Predicting 
Landslide Risk of Rohingya Refugee Camp Infrastructure. Journal of Information and Telecommunication, 4, 175-198. https://doi.org/10.1080/24751839.2019.1704114

[89] Green, C. (2018) Six Ways the UN Is Taking Action to Protect Rohingya Refugees This Monsoon Season.

[90] Rashid, S.R. (2020) Finding a Durable Solution to Bangladesh's Rohingya Refugee Problem: Policies, Prospects and Politics. Asian Journal of Comparative Politics, 5, 174-189. https://doi.org/10.1177/2057891119883700

[91] ISCG (2018) JRP for Rohingya Humanitarian Crisis: March-December 2018. Inter Sector Coordination Group.

https://reliefweb.int/report/bangladesh/jrp-rohingya-humanitarian-crisis-march-de cember-2018-0

[92] Amin, M. (2018) Nobody's Children, Owners of Nothing': Analysing the Indian State's Policy Response to the Rohingya Refugee Crisis. The Hindu Center for Politics and Public Policy, Chennai.

[93] Khan, M.A. (2017) Addressing the Challenges of Rohingya Refugees: Repatriation Issues. Review of Social Sciences, 3, 1-49.

[94] Mehta, K. and Kuschminder, P. (2018) Preventing a Monsoon Health Crisis in Bangladesh.

[95] WHO (2018) Rohingya Crisis in Cox’s Bazar District, Bangladesh. Health Sector Bulletin No. 6.

http://www.searo.who.int/bangladesh/healthsectorcxbbanbulletinn6.pdf

[96] ReliefWeb (2019) Humanitarian Action for Children 2019-Bangladesh. Report from UN Children's Fund, 30 January 2019.

https://reliefweb.int/report/bangladesh/humanitarian-action-children-2019-banglad esh

[97] ReliefWeb (2019) Two Years On: Rohingya Deserve Justice, a Place at the Table. https://reliefweb.int/report/bangladesh/two-years-rohingya-deserve-justice-place-ta ble

[98] REACH (2018) Water, Sanitation and Hygiene Baseline Assessment.

[99] Nyukuri, A.N. (2020) Coordination of the Nutrition Sector Response for Forcibly Displaced Myanmar Nationals in Cox's Bazar, Bangladesh. Field Exchange, 62, 24.

[100] Abir, A.H. (2019) The Nutritional Status on Rohingya Children (06 to 59 Months) with NAW Round-1.

[101] Kurkowska, M., Montangero, A. and Cippà, A. (2019) Dignifying Sanitation Services for the Rohingya Refugees in Cox's Bazar Camps. Rural 21, 53, 32-34.

[102] UNHCR (2019) Refugee Education 2030: A Strategy for Refugee Inclusion.

[103] Hammond, V. and Milko, C. (2019) UN, NGOs Accused of Bungling Effort to Educate Rohingya Children. Aljazeera.

[104] UNICEF (2020) Expanding Education for Rohingya Refugee Children in Bangladesh.

[105] Guglielmi, S., Muz, J., Mitu, K., Uddin, M.A., Jones, N., Baird, S. and Presler-Marshall, E. (2019) The Lives They Lead: Exploring the Capabilities of Bangladeshi and Rohingya Adolescents in Cox's Bazar, Bangladesh. Policy Brief, Gender and Adolescence: Global Evidence, London.

[106] Guglielmi, S., Jones, N., Muz, J., Baird, S., Mitu, K. and Uddin, M.A. (2020) “I Don’t Have Any Aspiration Because I Couldn't Study": Exploring the Educational Barriers Facing Adolescents in Cox's Bazar. 
[107] Bakali, N. and Wasty, S. (2020) Identity, Social Mobility, and Trauma: Post-Conflict Educational Realities for Survivors of the Rohingya Genocide. Religions, 11, 241. https://doi.org/10.3390/rel11050241

[108] UNICEF (2019) Beyond Survival: Rohingya Refugee Children in Bangladesh Want to Learn. UNICEF Advocacy Alert. Reliefweb.

[109] Guzek, J.W.K. and Siddiqui, R. (2017) Health Survey in Kutupalong and Balukhali Refugee Settlements. Cox's Bazar, Bangladesh Survey Report.

[110] IAWG (2018) Women and Girls Critically Underserved in the Rohingya Humanitarian Response.

[111] Parmar, P.K., Jin, R.O., Walsh, M. and Scott, J. (2019) Mortality in Rohingya Refugee Camps in Bangladesh: Historical, Social, and Political Context. Sexual and Reproductive Health Matters, 27, 39-49. https://doi.org/10.1080/26410397.2019.1610275

[112] Silove, D., Ventevogel, P. and Rees, S. (2017) The Contemporary Refugee Crisis: An Overview of Mental Health Challenges. World Psychiatry, 16, 130-139. https://doi.org/10.1002/wps.20438

[113] Morina, N., Akhtar, A., Barth, J. and Schnyder, U. (2018) Psychiatric Disorders in Refugees and Internally Displaced Persons after Forced Displacement: A Systematic Review. Frontiers in Psychiatry, 9, 433. https://doi.org/10.3389/fpsyt.2018.00433

[114] Kirmayer, L.J., Narasiah, L., Munoz, M., Rashid, M., Ryder, A.G., Guzder, J., Hassan, G., Rousseau, C. and Pottie, K. (2011) Common Mental Health Problems in Immigrants and Refugees: General Approach in Primary Care. Cmaj, 183, E959-E967. https://doi.org/10.1503/cmaj.090292

[115] Khan, N.Z., Shilpi, A.B., Sultana, R., Sarker, S., Razia, S., Roy, B., Arif, A., Ahmed, M.U., Saha, S.C. and McConachie, H. (2019) Displaced Rohingya Children at High Risk for Mental Health Problems: Findings from Refugee Camps within Bangladesh. Child: Care, Health and Development, 45, 28-35.

https://doi.org/10.1111/cch.12623

[116] UNHCR (2018) Strategic Plan for Mental Health and Psychosocial Support (MHPSS) for UNHCR's Rohingya Refugee Response 2018. Unpublished Report, UNHCR Cox's Bazar.

[117] Uddin, A. and Sumi, H. (2019) The Story of a Rohingya Refugee: Becoming a Community Psychosocial Volunteer. Intervention, 17, 296.

https://doi.org/10.4103/INTV.INTV_46_19

[118] Mahmuda, M., Miah, M.A.A., Elshazly, M., Khan, S., Tay, A.K. and Ventevogel, P. (2019) Contextual Adaptation and Piloting of Group Integrative Adapt Therapy (IAT-G) amongst Rohingya Refugees Living in Bangladesh. Intervention, 17, 149. https://doi.org/10.4103/INTV.INTV_48_19

[119] Tarannum, S., Elshazly, M., Harlass, S. and Ventevogel, P. (2019) Integrating Mental Health into Primary Health Care in Rohingya Refugee Settings in Bangladesh: Experiences of UNHCR. Intervention, 17, 130. https://doi.org/10.4103/INTV.INTV_34_19

[120] WHO (2005) Strengthening Health Security by Implementing the International Health Regulations. Global Outbreak Alert and Response Network (GOARN), World Health Organization, 2018.

http://www.who.int/ihr/alert_and_response/outbreak-network/en

[121] Alam, N., Kenny, B., Maguire, J.E., McEwen, S., Sheel, M. and Tolosa, M.X. (2019) Field Epidemiology in Action: An Australian Perspective of Epidemic Response to the Rohingya Health Emergencies in Cox's Bazar, Bangladesh. Global Biosecurity, 1, 
119. https://doi.org/10.31646/gbio.14

[122] Karo, B., Haskew, C., Khan, A.S., Polonsky, J.A., Mazhar, M.K.A. and Buddha, N. (2018) World Health Organization Early Warning, Alert and Response System in the Rohingya Crisis, Bangladesh, 2017-2018. Emerging Infectious Diseases, 24, 2074-2076. https://doi.org/10.3201/eid2411.181237

[123] Tolosa MX, S.L., Shirin, T., Yesurajan, F., Housen, T. and Stewart, A. (2018) Establishing Basic Public Health Laboratory Capacity in the Context of a Large-Scale Acute Refugee Crisis-Challenges and Lessons Learned. 9th Southeast Asia and Western Pacific Bi-Regional TEPHINET Scientific Conference, Vientiane, Lao People's Democratic Republic, 5-9 November 2018, 11.

[124] WHO (2015) The Global Strategy for Women's, WHO, 2015. The Global Strategy for Women's, Children's and Adolescents' Health (2016-2030). World Health Organization.

[125] Doedens, W.B.K. (2001) Challenges to Reproductive Health in Emergencies Health in Emergencies. Department of Emergency and Humanitarian Action.

[126] Ahmed, R., Farnaz, N., Aktar, B., Hassan, R., Shafique, S.B., Ray, P., Awal, A., Rahman, A., Urbaniak, V., Kobeissi, L.H. and Rosie, J. (2019) Situation Analysis for Delivering Integrated Comprehensive Sexual and Reproductive Health Services in Humanitarian Crisis Condition for Rohingya Refugees in Cox's Bazar, Bangladesh: Protocol for a Mixed-Method Study. BMJ Open, 9, e028340. https://doi.org/10.1136/bmjopen-2018-028340

[127] HSCT (2018) Rohingya Crisis in Cox’s Bazar, Bangladesh Health Sector Bulletin\#4.

[128] Doedens, W. and Burns, K. (2001) Challenges to Reproductive Health in Emergencies. WHO Heal. Emergencies Newsl.

[129] Shair, D., Akhter, K. and Shama, A. (2019) The Role of Psychosocial Support in Coping with Incidents of Gender-Based Violence among Rohingya Refugees. Intervention, 17, 238. https://doi.org/10.4103/INTV.INTV_16_19

[130] ReliefWeb (2017) Bangladesh: Humanitarian Situation Report No. 16 (Rohingya Influx), 24 December 2017.

[131] BBC (2018) The Rohingya Children Trafficked for Sex.

[132] AlJazeera (2019) Rohingya Girls Rescued from Traffickers in Bangladesh.

[133] Hossain, M.M., Sultana, A. and Das, A. (2018) Gender-Based Violence among Rohingya Refugees in Bangladesh: A Public Health Challenge. Indian Journal of Medical Ethics, 3, 260. https://doi.org/10.20529/IJME.2018.045

[134] OCHA (2019) Humanitarian Response: Gender Based Violence.

[135] UNFPA (2018) Sexual and Reproductive HEALTH Needs Immense among Rohingya Refugees.

[136] Severi, L. (2019) In Conversation with: HOPE Foundation for Women and Children of Bangladesh. United Nations Foundation.

[137] IOM (2017) Situation Report: Rohingya Refugee, Crisis Cox’s Bazar 2017.

[138] Chandan, M.S.K. (2018) Evicted from Rakhine, Trafficked in Cox's Bazar. The Daily Star.

[139] DNA (2019) More than 200 Rohingya Muslims Try to Enter Malaysia, 41 Arrested by Authorities.

https://www.dnaindia.com/world/report-more-than-200-rohingya-muslims-try-toenter-malaysia-41-arrested-by-authorities-2737619

[140] Banerji, A. (2019) Indian Police Rescue Suspected Rohingya Victims of Trafficking, 
Thomson Reuters.

https://in.reuters.com/article/india-rohingya-trafficking/indian-police-rescue-suspe cted-rohingya-victims-oftrafficking-idINKCN1SD0B5

[141] Yadav, U.R. (2019) Seven Rohingya Arrested at KIA with Fake Passports.

[142] Kamruzzaman, M. (2019) Lack of Future Prompts Rohingya to Flee Bangladesh. The Peninsula.

[143] Routray, B.P. (2019) Onwards Malaysia: Rohingya Focused Human Trafficking Networks. 